\title{
Final Diagnosis of Pediatric Patients with Prolonged in Activated Partial Thromboplastin Time Preoperative Study
}

\author{
Noemí Aguirre1, Francisca Córdova², Francisca Jaime³ ${ }^{3}$ Ximena Fonseca4, Pamela Zúñiga ${ }^{5}$ \\ ${ }^{1}$ Pediatrics Resident, Pontifical Catholic University of Chile, Santiago, Chile \\ ${ }^{2}$ School of Medicine, Pontifical Catholic University of Chile, Santiago, Chile \\ ${ }^{3}$ Pediatrician, Resident of Pediatric Gastroenterology and Nutrition, Pontifical Catholic University of Chile, \\ Santiago, Chile \\ ${ }^{4}$ Otorhinolaryngologist, Assistant Professor, Pediatrics Division, Medical School, Pontifical Catholic University of \\ Chile, Santiago, Chile \\ ${ }^{5}$ Hematologist-Oncologist, Assistant Professor, Pediatrics Division, Medical School, Pontifical Catholic \\ University of Chile, Santiago, Chile \\ Email: noemi.a.rioseco@gmail.com
}

Received 31 January 2015; accepted 16 May 2015; published 19 May 2015

Copyright @ 2015 by authors and Scientific Research Publishing Inc.

This work is licensed under the Creative Commons Attribution International License (CC BY).

http://creativecommons.org/licenses/by/4.0/

(c) (7) Open Access

\section{Abstract}

Introduction: Activated partial thromboplastin time (aPTT) is one of the most used coagulation tests in preoperative evaluation. Incidental detection of a prolonged aPTT is a problem in primary care, in which the general pediatrician should be able to attend its initial management. Objective: To describe final diagnosis of patients with prolonged aPTT in preoperative study. Materials and Methods: This is a descriptive study of patients referred from otorhinolaryngology. Results: Totally, 508 adenoidectomies and/or tonsillectomies were performed in our center, 38 of which referred patients $(\mathbf{7 . 5 \%})$ with prolonged aPTT, and 30 of which met inclusion criteria. The median age was 4 years. $56.6 \%$ of patients were males. $76.6 \%$ of patients normalized aPTT at the second follow-up. Among these, $73.9 \%$ showed a normal study, $4.3 \%$ ha2d lupus anticoagulant and in $21.7 \%$ Von Willebrand disease was detected. Among patients that persisted with prolonged aPTT, 42.8\% had coagulant factors deficiency, $28.5 \%$ had lupus anticoagulant and in $28.5 \%$ of patients a diagnosis could not be achieved with the tests used in the present study. Multivariate analysis did not show correlation between final diagnosis and the variables measured. Conclusion: The presence of a prolonged aPTT in children under preoperative study is due to a pre-analytic factor in the majority of cases or to the presence of lupus anticoagulant, normalizing values on follow-up. We suggest that a new aPTT be performed on these patients, and only those that persist altered or present a symptoms and family history of coagulation disorders be referred to hematology.

How to cite this paper: Aguirre, N., Córdova, F., Jaime, F., Fonseca, X. and Zúñiga, P. (2015) Final Diagnosis of Pediatric Patients with Prolonged in Activated Partial Thromboplastin Time Preoperative Study. International Journal of Otolaryngology and Head \& Neck Surgery, 4, 241-247. http://dx.doi.org/10.4236/ijohns.2015.43041 


\section{Keywords}

\section{aPTT, Preoperative Study, Tonsillectomy, Adenoidectomy, Coagulopathy}

\section{Introduction}

Activated partial thromboplastin time (aPTT) is one of the most used coagulation tests in the preoperative setting.

In this scenario, detection of an incidental prolonged aPTT is a concern in pediatric care, due to the fact that the test is commonly ordered without a history of bleeding [1], history that is difficult to obtain in younger patients that have not been exposed to hemorrhagic stress situations.

Among the pathologies that can cause a prolongation in the aPTT, there exist hereditary coagulopathies as isolated deficiencies in factors VIII, IX, XI, and XII and Von Willebrand disease with low VIII factor. There are also other acquired causes as the presence of heparin in the sample, being from treatment or contamination and the lupus anticoagulant (LA). This last one is caused by the presence of antiphospholipid antibodies, IgG and/or IgA immunoglobulins, which are present in almost $23 \%$ of apparently healthy children [2]-[4], most of all in the younger population [5] in which they are usually transitory in association with infections [4] [6] [7]. Duration in circulation of the lupus anticoagulant is not yet exactly known, but to be considered transitory, not related with autoimmune diseases as the antiphospholipid syndrome, it must be less than 12 weeks [6] [8]-[10].

To suspect the presence of LA, the aPTT study can be corrected by using a mix with normal plasma. This is done with a second aPTT with plasma from the patient, mixed with normal plasma from donors, in a 1:1 ratio. If there is a decrease in any coagulation factor, the new aPTT corrects to normal values. However, in the presence of LA, the aPTT will continue to be prolonged. To confirm this suspicion, there are various tests that can be used; in our institution, the test used is "dilute Russell viper venom".

There are few publications concerning this topic. Described groups reveal a prolonged aPTT in pediatric patients in preoperative study to be between $3 \%$ and $10 \%$ [11]-[15].

The present study will describe the final diagnosis of patients that have been found to have a prolonged aPTT, as an incidental finding in preoperative study for otorhinolaryngologic surgery. This will help guide general pediatricians in the course of action with this patient group, and will be the starting point for future investigations.

\section{Objectives}

\subsection{Main Objective}

To describe the final diagnosis of patients with prolonged aPTT in preoperative study.

\subsection{Specific Objectives}

1) To describe the distribution of patients with prolonged aPTT that resolve spontaneously on follow-up;

2) To describe the differences in this distribution based on:

a) Age and sex of patients;

b) Bleeding symptoms of the patient;

c) Family history of bleeding symptoms;

d) History of infection during the last month.

\section{Patients and Methods}

\subsection{Study Design}

The present study is descriptive and cross-sectional, with a prospective inclusion of patients by recruiting those that were seen in the ambulatory setting with preoperative study of otorhinolaryngologic (ORL) surgery at the Clinical Hospital of the Pontifical Catholic University of Chile with prolonged aPTT, between April 2013 and September 2014. aPTT is ordered routinely as part of the preoperative protocol for adenoidectomy with or without tonsillectomy. Inclusion and exclusion criteria are described in Table 1. 
Patients that accepted inclusion were seen by a hematologist-oncologist (hemostasis specialist) (Pamela Z.) in ambulatory setting, signed an informed consent previously accepted by the ethics committee of our center and completed an internationally validated questionnaire of bleeding symptoms, attached in Table 2 [16]. A bleeding score was calculated based on the questionnaire, being considered a significant result to have over 3 points in males and over 5 points in females. Tests used to assess the final diagnosis were those usually ordered for these patients (Table 3 ).

\section{Table 1. Patient selection.}

Inclusion criteria

Patients $<18$ years of age, and

Patients with aPTT over normal values in preoperative study for adenoidectomy and/or tonsillectomy, including tests not made in our laboratories, and

Patients that had follow-up study done in our laboratories

\section{Exclusion criteria}

Patients known to have a coagulopathy, or

Patients known to have liver disease

\section{Table 2. Questionnaire.}

\section{General data}

\begin{tabular}{l}
\hline Date \\
Last name \\
Names \\
Date of birth \\
Address \\
County
\end{tabular}

Bleeding score: Please assign a score for each symptom depending on its severity.

\begin{tabular}{|c|c|c|}
\hline Symptoms & Score & \\
\hline Epistaxis & $\begin{array}{l}0=\text { No or trivial } \\
2=\text { Packing, cauterization }\end{array}$ & $\begin{array}{l}1=\text { Present } \\
3=\text { Transfusion, replacement }\end{array}$ \\
\hline Cutaneous symptoms & $\begin{array}{l}0=\text { No or trivial } \\
2=\text { Hematomas }\end{array}$ & $\begin{array}{l}1=\text { Petechiae or bruises } \\
3=\text { Medical consultation }\end{array}$ \\
\hline Minor wounds & $\begin{array}{l}0=\text { No or trivial } \\
2=\text { Medical consultation }\end{array}$ & $\begin{array}{l}1=\text { Present }(1-5 \text { episodes } / \text { year }) \\
3=\text { Surgery } / \text { blood transfusion }\end{array}$ \\
\hline Oral cavity bleeding & $\begin{array}{l}0=\text { No or trivial } \\
2=\text { Medical attention }\end{array}$ & $\begin{array}{l}1=\text { Present } \\
3=\text { Surgery } / \text { blood transfusion }\end{array}$ \\
\hline Gastrointestinal bleeding & $\begin{array}{l}0=\text { No or trivial } \\
2=\text { Medical Attention }\end{array}$ & $\begin{array}{l}1=\text { Present } \\
3=\text { Surgery/blood transfusion }\end{array}$ \\
\hline Muscle hematomas of hemarthrosis & $\begin{array}{l}0=\text { No or trivial } \\
2=\text { Medical Attention }\end{array}$ & $\begin{array}{l}1=\text { Present } \\
3=\text { Transfusion/intervention }\end{array}$ \\
\hline Tooth extraction (most severe episode) & $\begin{array}{l}0=\text { No or trivial } \\
2=\text { Suturing of packing }\end{array}$ & $\begin{array}{l}1=\text { Present } \\
3=\text { Transfusion }\end{array}$ \\
\hline Surgery (most severe episode) & $\begin{array}{l}0=\text { No or trivial } \\
2=\text { Suturing or resurgery }\end{array}$ & $\begin{array}{l}1=\text { Present } \\
3=\text { Transfusion }\end{array}$ \\
\hline Menorrhagia & $\begin{array}{l}0=\text { No or trivial } \\
2=\text { Consultation, pill use, iron therapy }\end{array}$ & $\begin{array}{l}1=\text { Present } \\
3=\text { Transfusion, hysterectomy, dilatation-curettage, } \\
\text { replacement therapy }\end{array}$ \\
\hline
\end{tabular}

\section{Table 3. Tests ordered.}

Lupus anticoagulant: in our center the test used is the Dilute Russell Viper Venom; includes aPTT and correction with normal plasma mix in $1: 1$ ratio.

Von Willebrand disease study.

Only in the cases that prolonged aPTT was corrected with normal plasma were factors XII, IX, and XI measured. 


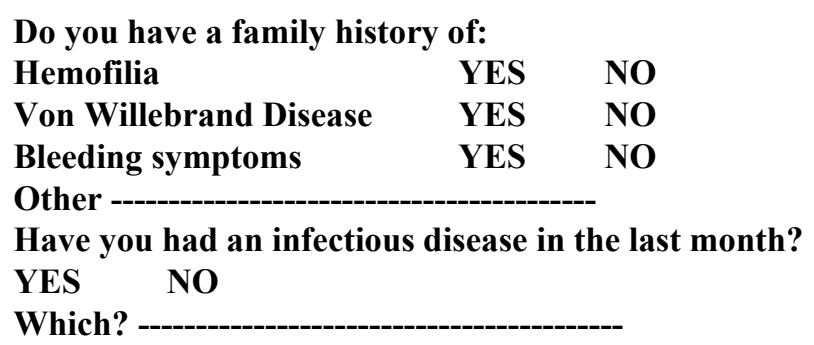

\subsection{Statistical Analysis}

Acquired data were input to an Excel database and were statistically analyzed with SPSS ${ }^{\circledR}$ version 20 . Final diagnosis of the patient was considered a dependent variable whilst ages, sex, personal history of bleeding, family history of bleeding and infectious disease in the last 4 weeks were considered independent. For numerical variables median and range were calculated, and for categorical values percentage distribution was calculated. As to compare differences for numerical variables among the different groups in final diagnosis we used the Kruskal-Wallis test and for nominal variables we used chi square test. Furthermost a multinomial logistic regression was made.

\section{Results}

During the studied period (16 months), 508 adenoidectomies and/or tonsillectomies were performed at our center. 66 total patients $(12.9 \%)$ were referred to our clinic from ORL, amongst which 38 (7.5\%) had prolonged aPTT and were included (Figure 1).

The 28 remaining patients $(5.5 \%)$ were referrals for prolonged bleeding time (20 patients), low partial thromboplast in time (7 patients) and thrombocytopenia (1 patient).

4 patients were excluded because of refusal to sign the informed consent, 2 patients did not complete the study and 2 patients were unreachable due to lack of assistance to follow-up.

Finally 30 patients with prolonged aPTT were followed, 3 of these had concomitant prolonged bleeding time, and 5 patients had concomitant low partial thromboplast in time. $73.3 \%$ had isolated prolonged aPTT.

Age median for prolonged aPTT patients was 4 years, $56.6 \%$ were male (Table 4 ).

Among the 30 recruited patients, 23 (76.6\%) patients normalized aPTT at follow-up, 17 (73.9\%) had normal follow-up study, 1 (4.3\%) had lupus anticoagulant detected and $5(21.7 \%)$ had Von Willebrand disease detected. (Figure 2).

Among patients that persisted with a prolonged aPTT, 3 patients $(42.8 \%)$ had coagulation factors deficiency, 2 patients $(28.5 \%)$ had lupus anticoagulant and in 2 patients $(28.5 \%)$ a final diagnosis could not be achieved during this study.

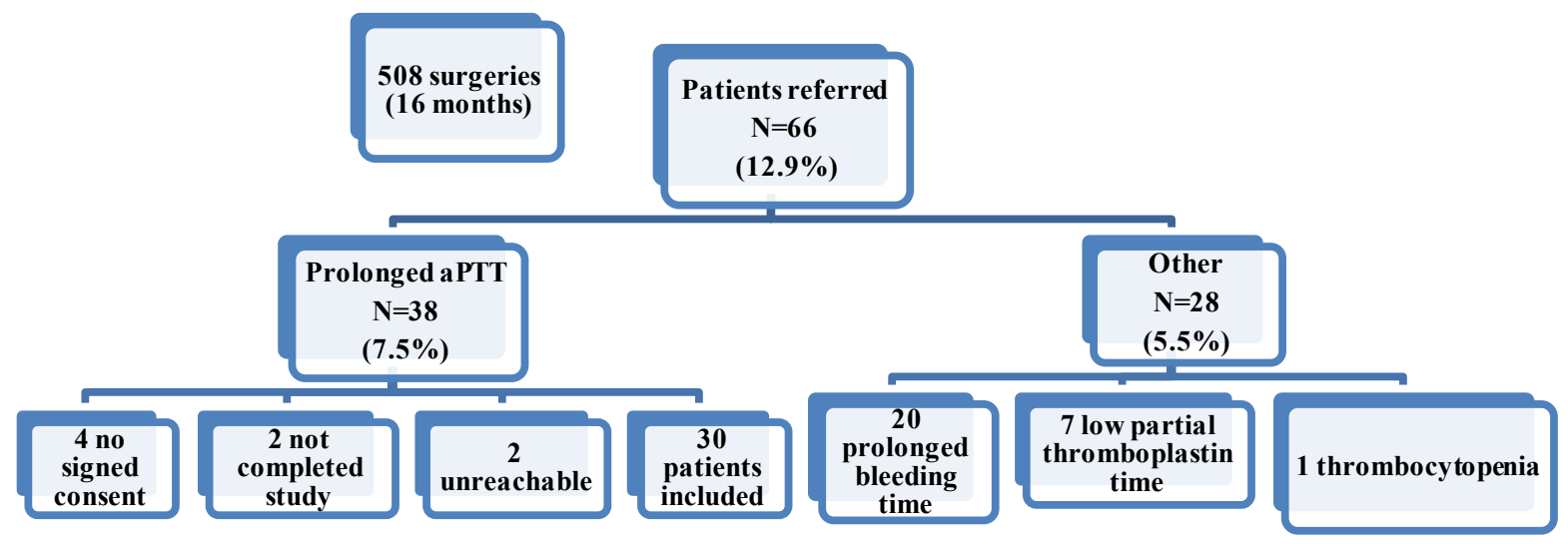

Figure 1. Distribution of patients. Shows how patients were recruited from referrals to the Otorhinolaryngology service, showing the number of excluded patients and the criteria for this exclusion. Additionally on the right branch we show other motives for referral due to altered hemostasis tests that were not the focus of the present study. 
Table 4. Characterization of patients.

\begin{tabular}{|c|c|c|c|c|c|c|}
\hline Variable & $\begin{array}{l}\text { Normal } \\
N=17\end{array}$ & $\begin{array}{c}\mathbf{L A} \\
\mathbf{N}=\mathbf{3}\end{array}$ & $\begin{array}{l}\text { Factor deficiency } \\
\qquad \mathbf{N}=\mathbf{3}\end{array}$ & $\begin{array}{l}\text { vWD } \\
\mathbf{N}=5\end{array}$ & $\begin{array}{c}\text { No identifiable } \\
\text { cause } N=2\end{array}$ & $\begin{array}{c}\text { Total } \\
\mathbf{N}=\mathbf{3 0}\end{array}$ \\
\hline Male, $\mathbf{N}(\%)$ & $\begin{array}{c}10 \\
(58.8 \%)\end{array}$ & $\begin{array}{c}2 \\
(66.6 \%)\end{array}$ & $\begin{array}{c}3 \\
(100 \%)\end{array}$ & $\begin{array}{c}2 \\
(40 \%)\end{array}$ & $\begin{array}{c}0 \\
(0 \%)\end{array}$ & $\begin{array}{c}17 \\
(56.6 \%)\end{array}$ \\
\hline Age in years, median (range) & $\begin{array}{c}4.0 \\
(3-12)\end{array}$ & $\begin{array}{c}2.0 \\
(2-7)\end{array}$ & $\begin{array}{c}4.0 \\
(1-6)\end{array}$ & $\begin{array}{c}3.0 \\
(2-5)\end{array}$ & $\begin{array}{c}5.0 \\
(4-6)\end{array}$ & $\begin{array}{c}4.0 \\
(1-12)\end{array}$ \\
\hline Bleeding score, median (range) & $\begin{array}{c}0 \\
(0-2)\end{array}$ & $\begin{array}{c}1 \\
(0-4)\end{array}$ & $\begin{array}{c}0 \\
(0)\end{array}$ & $\begin{array}{c}0 \\
(0-1)\end{array}$ & $\begin{array}{c}0 \\
(0-1)\end{array}$ & $\begin{array}{c}1 \\
(0-4)\end{array}$ \\
\hline Family history of bleeding, N (\%) & $\begin{array}{c}9 \\
(52.9 \%)\end{array}$ & $\begin{array}{c}0 \\
(0 \%)\end{array}$ & $\begin{array}{c}2 \\
(66.6 \%)\end{array}$ & $\begin{array}{c}3 \\
(60 \%)\end{array}$ & $\begin{array}{c}0 \\
(0 \%)\end{array}$ & $\begin{array}{c}14 \\
(46.6 \%)\end{array}$ \\
\hline Infectious disease during the last month, $\mathbf{N}(\%)$ & $\begin{array}{c}4 \\
(23.5 \%)\end{array}$ & $\begin{array}{c}1 \\
(33.3 \%)\end{array}$ & $\begin{array}{c}2 \\
(66.6 \%)\end{array}$ & $\begin{array}{c}0 \\
(0 \%)\end{array}$ & $\begin{array}{c}0 \\
(0 \%)\end{array}$ & $\begin{array}{c}7 \\
(23.3 \%)\end{array}$ \\
\hline
\end{tabular}

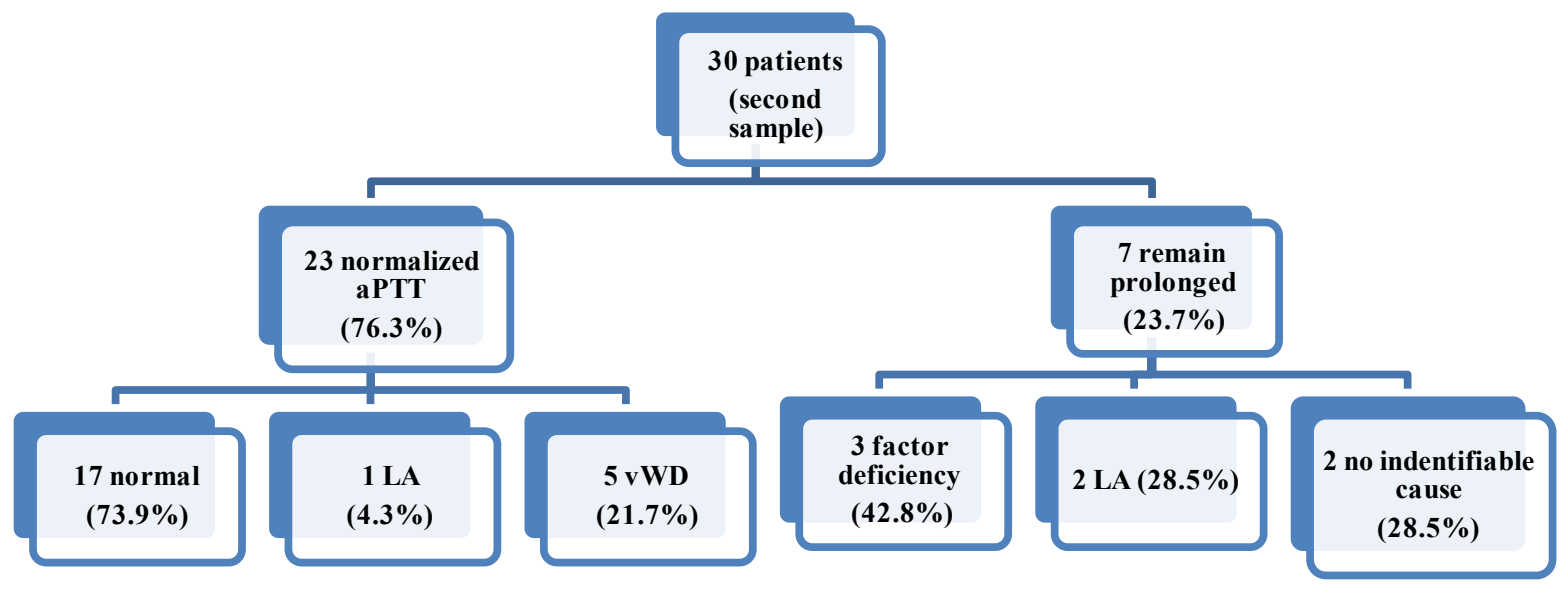

Figure 2. Results. Shows final diagnosis of patients after completing the tests included in our study.

Regarding the bleeding symptoms score, only 1 patient had a significant result and had lupus anticoagulant detected during further testing.

A family history of bleeding disorders was present in $52.9 \%$ of patients with normal follow-up tests, and in $66.6 \%$ of patients with coagulation factors deficiency, values that were not statistically different. However this history was not so clear due to confusion or ignorance of one or both parents.

During uni or multivariate analysis, there were no statistically significant differences amongst the variables analyzed (age, sex, bleeding score, family history of bleeding and history of infectious disease during the previous month) and the different final diagnosis of the patients.

\section{Discussion}

Tonsillectomy with or without adenoidectomy is the most frequent major surgical procedure in the pediatric patient [17].

A correct interpretation of coagulation tests when ordered is absolutely relevant given that the most frequent complication of this procedure is bleeding, being known to occur between $1 \%$ and $8 \%$ of total cases [17] [18]. It has been known that this risk is even greater amongst male patients, who in our study were the vast majority of patients referred for prolonged aPTT [17].

In our study, $7.5 \%$ of patients that had preoperative coagulation tests had a prolonged aPTT, figure that is within published ranges [11] [14] [15] [19].

Most of our patients normalized aPTT on second follow-up. This could be explained due to pre-analytic factors that were corrected, for example there are difficulties known regarding sample recovery from pediatric patients such as: anatomical conditions, or anxiety of the child, parent or caretaker. Another possibility is the presence of transitory LA, which correlates with the peak in prevalence of LA around 5 years of age reported by 
Male et al., corresponding with the age group analyzed in the present study [20] and the levels of LA reported as a cause of isolated prolonged aPTT in literature. These reports exceed the levels that we could confirm in our study (up to 53, 1\% v/s 10\% respectively) [2] [13] [14] [17] [21]. Looking back at the time interval between both samples obtained from our patients, most of these were retrieved after 3 months (average in weeks), which is greater than the time interval described for LA study in children [5] [6].

$26.6 \%$ of the patients with prolonged aPTT were found to have a possible coagulation disorder that had not been identified previously (Von Willebrand disease or a coagulation factor deficiency), similar to available literature [14].

Prolonged aPTT due to coagulation factor deficiency was not common (10\%), however it was higher if compared to published data [14] [17]. Every patient persisted with prolonged aPTT at follow-up. Frequency of vWD in our study was $16.6 \%(0,9 \%$ of all patients that had surgery), correlating with published data [14].

There are studies that show that a medical history of bleeding (family history or bleeding symptoms) has a better predictive value than coagulation tests for perioperative bleeding [18], however in pediatrics most of the patients have not been previously exposed to hemostatic stress to assign a greater value to personal history of bleeding; thus can be seen in the results of our study. Furthermore, there is a study that shows a frequency of $0.9 \%$ of positive clinical history in patients that have coagulation tests [13].

In the present study, no patient with probable coagulopathy (Von Willebrand disease or coagulation deficiency) had a significant bleeding score, this relates to the median age of 4 years. Given this fact, family history of bleeding gains importance, though not statistically significant, being present in $62.5 \%$ of these patients.

In light of present results, we think that if a prolonged aPTT is detected in preoperative study in an asymptomatic patient without family history, the test should be repeated in 12 weeks, taking pre-analytic factors into consideration. If the test to detect LA is available we recommend that it should be performed, and only those patients whose tests persist altered or those who have a positive personal or familiar history of bleeding be referred to a hematologist [2] [14] [22].

\section{Conclusions}

Prolonged aPTT in preoperative checkup is a frequent finding, being crucial a correct interpretation and course of action by the general pediatrician and the physician who performs the preoperative evaluation.

In children, the majority of cases are due to a pre-analytic factor or to the presence of lupus anticoagulant, normalizing values on follow-up testing.

It should be considered that mucocutaneous bleeding symptoms may not be present to orient a probable coagulopathy in this age group, which is why a family history of bleeding gains relevance.

We suggest repeating an aPTT in these children and referring to a hematologist those that persist with altered results or a family history of bleeding disorders.

\section{Future Projections}

To propose a management algorithm for children that are seen by general pediatricians due to a prolonged aPTT found incidentally, thus avoiding unnecessary referrals of these patients, which are costly and are not always available, furthermore avoiding high costs of specific exams on these children.

Additionally, this study could help future investigations in which the primary objective is to know if a relation between a prolonged aPTT and the presence of perioperative bleeding exists.

\section{Acknowledgements}

The authors wish to thank Rodrigo Donoso Martínez M. D. for his collaboration in translating the present study to the English language.

\section{References}

[1] Anjali, A. and Steven, W. (2008) Bleeding Disorders. Pediatrics in Review, 29, 121-130. http://dx.doi.org/10.1542/pir.29-4-121

[2] Shah, M., O'Riordan, M. and Alexander, S. (2006) Evaluation of Prolonged aPTT Values in the Pediatric Population. Clinical Pediatrics, 45, 347-353. http://dx.doi.org/10.1177/000992280604500407 
[3] Edlinger, G., Gallistl, S. and Muntean, W. (1996) Lupus Anticoagulant and Factor XII Activity in Children with Prolonged PTT. Thrombosis Research, 83, 403-404. http://dx.doi.org/10.1016/0049-3848(96)00150-8

[4] Katrin, F., Karl, L. and Philipp, V. (2005) Antiphospholipid Antibodies in Pediatric Patients with Prolonged Activated Partial Thromboplastin Time during Infection. Immunobiology, 210, 799-805.

http://dx.doi.org/10.1016/j.imbio.2005.10.012

[5] Shiomou, K., Galanakis, E., Tzoufi, M., Tsaousi, C. and Papadopoulou, Z.L. (2002) Transient Lupus Anticoagulant and Prolonged Activated Partial Thromboplastin Time Secondary to Epstein-Barr Virus Infection. Scandinavian Journal of Infectious Diseases, 34, 67-69. http://dx.doi.org/10.1080/003655402753395229

[6] Mizumoto, H., Maihara, T., Hiejima, E., Shiota, M., Hata, A., Seto, S., Atsumi, T., Koike, T. and Hata, D. (2006) Transient Antiphospholipid Antibodies Associated with Acute Infections in Children: A Report of Three Cases and a Review of the Literature. European Journal of Pediatrics, 165, 484-488. http://dx.doi.org/10.1007/s00431-006-0117-0

[7] Blank, M., Krause, I., Fridkin, M., Keller, N., Kopolovic, J., Goldberg, I., Tobar, N. and Shoenfeld, Y. (2002) Bacterial Induction of Autoantibodies to Beta2-Glycoprotein-I Accounts for the Infectious Etiology of Antiphospholipid Syndrome. The Journal of Clinical Investigation, 109, 797-804. http://dx.doi.org/10.1172/JCI0212337

[8] Bermejo, A., Gonzalez, H., Abad, A., Figueroa, L., Muñoz, R., Marcos, M., Cebeira, M.J. and Alvarez, F.J. (2013) Anticoagulante lúpico en pediatria. Experiencia en nuestro centro. Boletín de la sociedad de pediatría de asturias, cantabria, castilla y león, 53, 146-151.

[9] Lippi, G., Salvagno, G.L., Rugolotto, S., Chiaffoni, G.P., Padovani, E.M., Franchini, M. and Guidi, G.C. (2007) Routine Coagulation Tests in Newborn and Young Infants. Journal of Thrombosis and Thrombolysis, 24, 153-155. http://dx.doi.org/10.1007/s11239-007-0046-4

[10] Hoyos López, M.C., Pascual Pérez, J.M., Blanco Quirós, A., Guerola Delgado, D., Valbuena Crespo, C. and Álvarez Guisasola, G. (1999) Anticoagulante lúpico en pediatria. Presentación de 4 casos. Anales Españoles de Pediatria, 51, 637-642.

[11] Marioni, G. and de Filippi, C. (2009) Pediatric Otolaryngologic Manifestations of Bleeding Disorders. International Journal of Pediatric Otorhinolaryngology, 735, S61-S64. http://dx.doi.org/10.1016/S0165-5876(09)70012-6

[12] Chng, W.J., Sum, C. and Kuperan, P. (2005) Causes of Isolated Prolonged Activated Partial Thromboplastin Time in an Acute Care General Hospital. Singapore Medical Journal, 46, 450-246.

[13] Gabriel, P., Mazoit, X. and Ecoffey, C. (2000) Relationship between Clinical History, Coagulation Tests, and Perioperative Bleeding during Tonsillectomies in Pediatrics. Journal of Clinical Anesthesia, 12, 288-291. http://dx.doi.org/10.1016/S0952-8180(00)00164-1

[14] Sandoval, C., Garcia, C., Visintainer, P., Ozkaynak, M.F. and Jayabose, S. (2003) The Usefulness of Preoperative Screening for Bleeding Disorders. Clinical Pediatrics, 42, 247-250. http://dx.doi.org/10.1177/000992280304200308

[15] Asaf, T., Reuveni, H., Yermiahu, T., Leiberman, A., Gurman, G., Porat, A., Schlaeffer, P., Shifra, S. and Kapelushnik, J. (2001) The Need for Routine Pre-Operative Coagulation Screening Tests (Prothrombin Time PT/Partial Thromboplastin Time PTT) for Healthy Children Undergoing Elective Tonsillectomy and/or Adenoidectomy International. International Journal of Pediatric Otorhinolaryngology, 61, 217-222. http://dx.doi.org/10.1016/S0165-5876(01)00574-2

[16] Rodeghiero, F., Castaman, G., Tosetto, A., Batlle, J., Baudo, F., Cappelletti, A., Casana, P., de Bosch, N., Eikenboom, J.C., Federici, A.B., Lethagen, S., Linari, S. and Srivastava, A. (2005) The Discriminant Power of Bleeding History for the Diagnosis of von Willebrand Disease Type 1: An Interntional, Multicenter Study. Journal of Thrombosis and Haemostasis, 3, 2619-2626. http://dx.doi.org/10.1111/j.1538-7836.2005.01663.x

[17] Windfuhr, J.P. and Chen, Y.S. (2002) Incidence of Post-Tonsillectomy Hemorrhage in Children and Adults: A Study of 4848 Patients. Ear, Nose \& Throat Journal, 81, 626-628.

[18] Zagólski, O. (2010) Hemorragia postamigdalectomía: ¿tienen las pruebas de coagulación y el historial de coagulopatía un valor predictivo? Acta Otorrinolaringológica Española, 61, 287-292. http://dx.doi.org/10.1016/j.otorri.2010.01.017

[19] Koshkareva, Y.A., Cohen, M., Gaughan, J.P., Callanan, V. and Szeremeta, W. (2012) Utility of Preoperative Hematologic Screening for Pediatric Adenotonsillectomy. Ear, Nose Throat Journal, 91, 346-356.

[20] Li, J., Lai, X., Yan, C., Xu, A., Nie, L., Zhou, Y., Liao, C. and Ren, H. (2009) Age-Associated Developmental Changes in the Activated Partial Thromboplastin Time (aPTT) and Causes of Prolonged aPTT Values in Healthy Chinese Children. Clinical Chemistry and Laboratory Medicine, 47, 1531-1537. http://dx.doi.org/10.1515/CCLM.2009.339

[21] Burk, C.D., Miller, L., Handler, S.D. and Cohen, A.R. (1992) Preoperative History and Coagulation Screening in Children Undergoing Tonsillectomy. Pediatrics, 89, 691-695. http://dx.doi.org/10.1097/00132586-199212000-00035

[22] Genecov, D.G., Por, Y.C., Barcelo, C.R., Salyer, K.E., Mulne, A.F. and Morad, A.B. (2005) Preoperative Screening for Coagulopathy Using Prothrombin Time and Partial Thromboplastin Time in Patients Requiring Primary Cranial Vault. Plastic and Reconstructive Surgery, 116, 389-394. http://dx.doi.org/10.1097/01.prs.0000172760.79803.68 